\title{
Treating invasive aspergillosis in patients with hematologic malignancy: diagnostic- driven approach versus empiric therapies
}

\author{
Rita Wilson Dib, Ray Y. Hachem*', Anne-Marie Chaftari, Fady Ghaly, Ying Jiang and Issam Raad
}

\begin{abstract}
Background: Early antifungal therapy for invasive aspergillosis (IA) has been associated with improved outcome. Traditionally, of empiric antifungal therapy has been used for clinically suspected IA. We compared outcomes of patients with hematologic malignancy and IA who were treated with voriconazole using the diagnostic driven DDA (DDA-Vori) that includes galactomannan testing vs. empiric therapy with a non-voriconazole-containing regimen (EMP-non-Vori) or empiric therapy with voriconazole (EMP-Vori).

Methods: We retrospectively reviewed the medical records of 342 hematologic malignancy patients diagnosed with proven, or probable IA between July 1993 and February 2016 at our medical center who received at least 7 days of DDA-Vori, EMP-Vori, or EMP-non-Vori. Outcome assessment included response to therapy (clinical and radiographic), all-cause mortality, and IA-attributable mortality.

Results: By multivariate analysis, factors predictive of a favorable response included localized/sinus IA vs. disseminated/pulmonary IA ( $p<0.0001)$, not receiving white blood cell transfusion $(p<0.01)$, and DDA-Vori vs. EMP-non-Vori $(p<0.0001)$. In contrast, predictors of mortality within 6 weeks of initiating IA therapy included disseminated/pulmonary infection vs. localized/sinus IA $(p<0.01)$, not undergoing stem cell transplantation within 1 year before IA $(p=0.01)$, and EMP-non-Vori vs. DDA-Vori $(p<0.001)$.

Conclusions: DDA-Vori was associated with better outcome (response and survival) compared with EMP-non-Vori and with equivalent outcome to EMP-Vori in hematologic malignancy patients. These outcomes associated with the implementation of DDA could lead to a reduction in the unnecessary costs and adverse events associated with the widespread use of empiric therapy.
\end{abstract}

Keywords: Invasive aspergillosis, Diagnostic driven therapy, Empiric therapy, Voriconazole, Cancer

\section{Background}

Invasive aspergillosis (IA) in patients with hematologic malignancies and in patients undergoing hematopoietic stem cell transplantation (HSCT) is still associated with high morbidity and mortality rates [1-3]. Early antifungal therapy has been associated with better outcomes; however, diagnosing IA with use of conventional diagnostic methods can be challenging because of the nonspecific clinical features of the disease and because the diagnosis is histopathologically and microbiologically

\footnotetext{
*Correspondence: rhachem@mdanderson.org

Department of Infectious Diseases, Infection Control \& Employee Health, Unit 1460, The University of Texas MD Anderson Cancer Center, 1515 Holcombe Blvd, Houston, TX, USA
}

(c) The Author(s). 2018 Open Access This article is distributed under the terms of the Creative Commons Attribution 4.0 International License (http://creativecommons.org/licenses/by/4.0/), which permits unrestricted use, distribution, and reproduction in any medium, provided you give appropriate credit to the original author(s) and the source, provide a link to the Creative Commons license, and indicate if changes were made. The Creative Commons Public Domain Dedication waiver (http://creativecommons.org/publicdomain/zero/1.0/) applies to the data made available in this article, unless otherwise stated. the current practice of early initiation of empiric antifungal therapy with an anti-mold agent in patients with suspected IA. However, this excessive and non-targeted therapy may lead to unnecessary adverse effects and high medical costs while increasing the risk of antifungal resistance $[4,5]$.

In recent years, novel diagnostic tools have been evaluated to improve the assessment and treatment of patients with IA. The sensitivity of Aspergillus galactomannan (GM) enzyme immunoassay testing is $82 \%$ (ranges from 73 to $90 \%$ ) and its specificity is $81 \%$ (ranges from 72 to $90 \%$ ) in the immunocompromised population who are not receiving anti-mold therapy or prophylaxis 
[6, 7]. In addition, specific radiological findings detected on high-resolution computed tomographic (CT) scans highly correlated with the presence of fungal infection $[8,9]$. These advances in diagnostic techniques, may help the clinician to establish an early diagnosis and rapidly initiate a diagnostic driven treatment instead of the current empiric approach that may lead to unnecessary treatment to certain patients.

Voriconazole is now the preferred anti-mold agent for primary therapy of IA, particularly in high-risk patients. Recommended alternative agents include liposomal amphotericin B caspofungin and/or isavuconazole [10].

The purpose of this study was to compare the diagnostic-driven approach (DDA) using voriconazole (DDA-Vori) with the currently used empiric approach consisting of either a regimen that did not contain voriconazole (EMP-non-Vori) or one that did contain voriconazole (EMP-Vori) as primary therapy for IA diagnosed on the basis of radiographic findings and positive GM antigen test or microbiological culture.

\section{Methods}

This was a retrospective study of patients with hematological malignancies that were diagnosed with probable or proven invasive aspergillosis at our institution from July 1993 to February 2016. This study was approved by our Institutional Review Board and waiver of informed consent was granted.

From MD Anderson's microbiology laboratory database, we extracted all patients $(n=604)$ who had had either hematologic malignancies or were post-HSCT with evidence of Aspergillus species growing in cultures obtained from sites of infection driven by clinical and radiological clues. We included patients equal and older than 14 years of age. Proven or probable IA was classified according to criteria from the European Organization for Research and Treatment of Cancer/Invasive Fungal Infections Cooperative Group and the National Institute of Allergy and Infectious Diseases Mycoses Study Group (EORTC/MSG) [11]. Patients with other types of malignancies such as solid tumors were excluded. We collected datafrom electronic patient medical records including relevant information on HSCT performed within the year prior to the diagnosis as well as antifungal therapy received for the treatment of IA, and prophylaxis if applicable. We excluded patients who received less than 7 days of antifungal therapy.

The diagnosis was based on positive aspergillus culture before 2002 or either a positive GM result (GM considered positive if index value was above 0.8 or 2 consecutive values ranged between 0.5 and 0.8 ) whether from serum [12] or from bronchoalveolar lavage (BAL) [13] and/or positive fungal culture for the period after 2002 since GM test was available at our institution. Patients with pulmonary diseases should have a CT scan suggestive of invasive fungal infection. Outcome information included response to therapy, all-cause mortality, IA-attributable mortality, and adverse events.

We compared the efficacy of therapy in patients who received DDA-Vori regimen with those who received an EMP-non-Vori regimen as well as with patients who received an EMP-Vori regimen. The main antifungal in the DDA-vori and EMP-Vori regimen consisted of voriconazole whereas the main antifungal in the non-vori group consisted of polyenes, echinocandins or other azoles than voriconazole.

\section{Definitions}

Diagnostic-driven therapy was defined as any therapy initiated in patients with underlying malignancy or in those who underwent HSCT provided that therapy was initiated after the diagnosis of IA was established, this approach included the 'pre-emptive' component defined previously by authors in similar studies [5, 14].

In empiric therapy, anti-mold therapy was initiated in patients before a positive GM or fungal culture was obtained ignited by clinical and radiological drivers.

Breakthrough infection is noted upon the occurrence of proven or probable invasive aspergillosis while the patient is on prophylaxis.

Response to primary therapy was defined as improvement or stabilization of the clinical signs and symptoms assessed by the treating physician and or radiological findings after receiving at least 7 days of same antifungal therapy.

\section{Statistical methods}

Categorical variables were compared using Chi-square or Fisher's exact test, as appropriate. Continuous variables were compared using Wilcoxon rank sum test. Logistic regression analysis was used to evaluate the independent effect of primary therapy on response. Similarly, Cox proportional hazards regression analysis and competing risk analysis were used to evaluate the independent effect of primary therapy on all-cause mortality and IA-attributable mortality, respectively. In addition, Kaplan-Meier survival curves were estimated for patients with different primary therapies and compared using a log-rank test. The cumulative incidence curves of IA-attributable mortality were also estimated with use of competing risk analysis. All tests were two-sided with a significance level of 0.05. Statistical analyses were performed using SAS version 9.3 (SAS Institute Inc., Cary, NC) and R version 2.15. 0 (R Development Core Team, 2008).

\section{Results}

A total of 342 patients fulfilled all inclusion criteria and were included in the study. They consisted of 44 in the DDA-Vori group, 221 in the EMP-non-Vori group, and 
77 in the EMP-Vori group. Patients' clinical characteristics, response to treatment, all-cause and IA-associated mortalities were analyzed.

\section{Basic characteristics of the three groups}

The majority of IA cases had invasive pulmonary infection (84\%) and fulfilled the criteria for proven or probable disease. Overall, $75 \%$ were patients with leukemia and $39 \%$ had undergone HSCT. Aspergillus fumigatus was the most common isolate observed in the patients (36\%), followed by Aspergillus terreus (22\%), Aspergillus flavus (21\%), and Aspergillus niger (13\%). The fungal species isolated also included Aspergillus versicolor and Aspergillus nidulans. The three groups were similar with respect to gender and IA categories.

Patients in both empiric groups were more likely to have neutropenia at the time of infection compared with the diagnostic-driven group (56\% for EMP-non-Vori vs $19 \%$ for DDA-Vori, $p<0.0001 ; 40 \%$ for EMP-Vori vs $19 \%$ for DDA-Vori, $p=0.02$ ). It is to note that $80.5 \%$ of the patients in the EMP-non-Vori group received an antifungal regimen that contained the lipid formulation of amphotericin B. In addition, the two empiric groups significantly received more active immunotherapy when compared with the DDA group (70\% for EMP-non-Vori vs $23 \%$ for DDA-Vori, $p<0.0001$; $49 \%$ for EMP-Vori vs $23 \%$ for DDA-Vori, $p=0.006$ ). They were also more likely to have received prophylactic antifungal treatment before therapy (35\% for EMP-non-Vori vs $16 \%$ for DDA-Vori, $p=0.012,36 \%$ for EMP-Vori vs $16 \%$ for DDA-Vori, $p=0.022$ ).

By univariate analysis, the response to therapy was significantly higher in the DDA-Vori group (73\%) than in the EMP-Vori $(51 \%, p=0.018)$ or EMP-non-Vori $(14 \%$, $p<0.0001)$ groups. All-cause mortality was not different between the two voriconazole-based therapies $(5 \%$ vs $9 \%, p=0.48$ ) but was significantly different when DDA-Vori therapy was compared with EMP-non-Vori therapy ( $5 \%$ vs $56 \%, p<0.0001$ ) (Tables 1 and 2 ). Similar results found by analyzing IA-attributable mortality.

\section{Predictors of response to primary therapy}

By multivariate analysis, factors independently associated with response to therapy included the type of IA infection $(p<0.001)$, whereby pulmonary and disseminated infections were 0.12 (95\% confidence interval [CI]: 0.04 to 0.34$)$ and $0.02(95 \% \mathrm{CI}:<0.01$ to 0.16$)$ times as likely to have a response when compared with localized/sinus infection, respectively (Table 3 ).

Patients receiving white blood cells were less likely to have a favorable response than were those not receiving white blood cells $(\mathrm{OR}=0.21,95 \% \mathrm{CI}$ : 0.05 to $0.66, p=0.005)$.
Multivariate analysis also showed a significant effect of primary therapy on response $(p<.0001)$. Patients in the EMP-non-Vori group were less likely to have a favorable response compared with those in the DDA-Vori group $(\mathrm{OR}=0.05,95 \% \mathrm{CI}: 0.02$ to $0.12, p<0.0001)$. In contrast, there was no significant difference in response between the two Vori groups $(p=0.06)$ (Table 3).

\section{Predictors of mortality within 6 weeks of initiation of IA therapy}

A definite diagnosis was a significant predictor of all-cause mortality at 6 weeks (HR 1.5, 95\% CI: 1.1 to 2.2). Invasive pulmonary disease and disseminated disease were 3.3 (95\% CI: 1.5 to 7.2 ) and 4.0 (95\% CI: 1.6 to 10.3 ) times more likely to be associated with overall mortality than localized or sinus infection respectively. Having undergone HSCT within 1 year of IA infection was associated with a lower mortality rate (HR 0.60, 95\% CI: 0.41 to $0.88, p=0.008$ ). Patients with antimold antifungal prophylaxis were also less likely to have an all-cause mortality $(\mathrm{HR}=0.61,95 \% \mathrm{CI}$ : 0.41 to 0.90). Patients treated with EMP-non-Vori were 18.8 times (95\% CI: 4.4 to $72.4, p<0.0001$ ) more likely to die than were those in the DDA-Vori group. Empiric and diagnostic-driven therapies with voriconazole were comparable in mortality $(p=0.34)$ (Table 4).

Regarding IA-attributed mortality, we found similar independent predictors. In addition, having had the infection during the years 1993 to 2004 was associated with a 1.8 times (95\% CI: 1.1 to 2.8) higher likelihood of IA-attributable mortality than was having had the infection in later years $(2005-2016)(p=0.012)$. Compared with the DDA-Vori group, patients receiving EMP-non-Vori were 9.8 times (95\% CI: 2.4 to 40.7 ) more likely to die of the infection $(p=0.002)$, and those receiving EMP-Vori showed no significant difference $(p=0.51)$.

Kaplan-Meier survival analysis also showed that the DDA-Vori group was associated with better survival rates than was the EMP-non-Vori group $(p<0.0001)$, but there was no significant difference between the DDA-Vori group and the EMP-Vori group ( $p=0.47$ ) (Fig. 1).

The duration (days) between IA diagnosis and starting primary therapy for the DDA-Vori group showed an interquartile range of 6 to 19 days and a median of 8 days. One hundred and nine patients in the study received GM tests within +/-1 week of IA diagnosis, of whom 30 had positive results and 79 had negative results. Patients with positive GM tests had numerically but not statistically worse outcomes than those with negative GM tests, including response to primary therapy $(33 \%$ vs $44 \%, p=0.30)$, all-cause mortality ( $34 \%$ vs $21 \%, p=0.13)$ and IA-attributed mortality (21\% vs $17 \%$, $p=0.59$ ). 
Table 1 Comparing patients under diagnostic-driven therapy with voriconazole and those under empiric antifungal therapy without voriconazole

\begin{tabular}{|c|c|c|c|}
\hline Characteristics and outcomes & $\begin{array}{l}\text { Diagnostic-driven therapy } \\
\text { with voriconazole } \\
(n=44) \\
N(\%)\end{array}$ & $\begin{array}{l}\text { Empiric antifungal therapy } \\
\text { without voriconazole } \\
(n=221) \\
N(\%)\end{array}$ & $p$-value \\
\hline Age (years), median (range) & $63(23-81)$ & $51(14-80)$ & $<0.001$ \\
\hline Gender, male & $26(59)$ & $131(59)$ & 0.98 \\
\hline Diagnosis of IA & & & $<.001$ \\
\hline Definite IA & 4/43 (9) & $83(38)$ & \\
\hline Probable IA & $39 / 43(91)$ & $138(62)$ & \\
\hline Invasive pulmonary infection ${ }^{a}$ & $40(91)$ & $178(81)$ & 0.10 \\
\hline Disseminated infection ${ }^{a}$ & $2(5)$ & $18(8)$ & 0.41 \\
\hline Localized or sinus infection $^{a}$ & $4(9)$ & $28(13)$ & 0.51 \\
\hline Leukemia & $19(43)$ & $181 / 220(82)$ & $<.0001$ \\
\hline Lymphoma & $16(36)$ & $34 / 220(15)$ & 0.001 \\
\hline Myeloma & $8(18)$ & $5 / 220(2)$ & $<.001$ \\
\hline Transplantation within 1 year prior to infection & $16(36)$ & $82 / 220(37)$ & 0.91 \\
\hline Type of transplantation within prior year & & & 0.010 \\
\hline Allogeneic transplant & 10/16 (63) & $74 / 82(90)$ & \\
\hline Autologous transplant & $6 / 16(38)$ & $8 / 82(10)$ & \\
\hline Graft vs Host Disease (GVHD) & $8 / 10(80)$ & $52 / 74(70)$ & 0.72 \\
\hline Neutropenia $(<500$ ANC) at onset of IA & $8 / 42(19)$ & $120 / 216(56)$ & $<.0001$ \\
\hline Persistent neutropenia & 14/36 (39) & $87 / 210(41)$ & 0.77 \\
\hline Received immunotherapy & 10/43 (23) & $154 / 220(70)$ & $<.0001$ \\
\hline Received WBC transfusion & $2 / 42(5)$ & $45(20)$ & 0.016 \\
\hline Year of IA diagnosis/treatment & & & $<.0001$ \\
\hline 1993-2004 & $8(18)$ & $162(73)$ & \\
\hline $2005-2016$ & $36(82)$ & $59(27)$ & \\
\hline Prophylactic antifungal treatment prior to & $7(16)$ & $78(35)$ & 0.012 \\
\hline \multicolumn{4}{|l|}{ infection } \\
\hline Breakthrough & 6/7 (86) & $67 / 78(86)$ & $>.99$ \\
\hline Response to therapy & $32(73)$ & $30(14)$ & $<.0001$ \\
\hline Death within 42 days of starting therapy & $2(5)$ & $123 / 220(56)$ & $<.0001$ \\
\hline Aspergillosis-attributable death within 42 days of starting therapy & $2(5)$ & 107/218 (49) & $<.0001$ \\
\hline
\end{tabular}

\section{Discussion}

In our study, we found that DDA-Vori therapy for IA based on GM biomarkers and microbiologic evidence had significantly better survival rates and response rates than did the non-vori-containing empiric approach. In addition, the DDA-Vori approach had equivalent outcomes (response and survival) to those observed with EMP-Vori therapy. It is also important to note that the median 8-day time delay between diagnosis and treatment in the DDA-Vori treatment group did not impact negatively on the outcomes compared to immediate empirical anti-fungal therapy.
The first randomized trial to support empiric antifungal therapy was published in 1982 [15]. To this day, the empiric approach is accepted as the standard of care in most daily clinical practices [16]. Several attempts were made to base antifungal therapy on a diagnostic strategy [14, 17-21]. In 2005, Maertens et al. [19] performed a diagnostic evaluation encompassing clinical, serial GM, and microbiological factors in a high-risk population with neutropenia and fever. Maertens followed a protocol whereby only those who had clinical signs and symptoms and tested positive were treated with liposomal amphotericin $\mathrm{B}$. This resulted in a decrease in the 
Table 2 Comparing patients under diagnostic-driven therapy with voriconazole and those under empiric antifungal therapy with voriconazole Characteristics

\begin{tabular}{|c|c|c|c|}
\hline \multirow[t]{3}{*}{ Characteristics and outcomes } & $\begin{array}{l}\text { Diagnostic-driven therapy } \\
\text { with voriconazole }\end{array}$ & $\begin{array}{l}\text { Empiric antifungal } \\
\text { therapy with } \\
\text { voriconazole }\end{array}$ & \multirow[t]{3}{*}{$p$-value } \\
\hline & $(n=44)$ & $(n=77)$ & \\
\hline & $N(\%)$ & $N(\%)$ & \\
\hline Age (years), median (range) & $63(23-81)$ & $58(22-86)$ & 0.10 \\
\hline Gender, male & $26(59)$ & $46(60)$ & 0.94 \\
\hline \multicolumn{3}{|l|}{ Diagnosis of IA } & \multirow[t]{3}{*}{0.06} \\
\hline Definite IA & 4/43 (9) & $18(23)$ & \\
\hline Probable IA & $39 / 43(91)$ & $59(77)$ & \\
\hline Invasive pulmonary infection ${ }^{a}$ & $40(91)$ & $68(88)$ & 0.77 \\
\hline Disseminated infection ${ }^{\mathrm{a}}$ & $2(5)$ & $6(8)$ & 0.71 \\
\hline Localized or sinus infection $^{a}$ & $4(9)$ & $3(4)$ & 0.25 \\
\hline Leukemia & $19(43)$ & $55(71)$ & 0.002 \\
\hline Lymphoma & $16(36)$ & $16(21)$ & 0.06 \\
\hline Myeloma & $8(18)$ & $4(5)$ & 0.029 \\
\hline Transplantation within 1 year prior to infection & $16(36)$ & $34(44)$ & 0.40 \\
\hline \multicolumn{3}{|l|}{ Type of transplantation within prior year } & \multirow[t]{3}{*}{0.14} \\
\hline Allogeneic transplant & 10/16 (63) & 29/34 (85) & \\
\hline Autologous transplant & $6 / 16(38)$ & $5 / 34(15)$ & \\
\hline Graft vs Host Disease (GVHD) & $8 / 10(80)$ & $22 / 29(76)$ & $>.99$ \\
\hline Neutropenia $(<500$ ANC) at onset of IA & $8 / 42(19)$ & 29/73 (40) & 0.022 \\
\hline Persistent neutropenia & 14/36 (39) & 21/64 (33) & 0.54 \\
\hline Received immunotherapy & $10 / 43(23)$ & $37 / 76(49)$ & 0.006 \\
\hline Received WBC transfusion & $2 / 42(5)$ & $8(10)$ & 0.49 \\
\hline \multicolumn{3}{|l|}{ Year of IA diagnosis/treatment } & \multirow[t]{3}{*}{0.73} \\
\hline 1993-2004 & $8(18)$ & $16(21)$ & \\
\hline $2005-2016$ & $36(82)$ & $61(79)$ & \\
\hline Prophylactic antifungal treatment prior to & $7(16)$ & 27/76 (36) & 0.022 \\
\hline \multicolumn{4}{|l|}{ infection } \\
\hline Breakthrough & 6/7 (86) & 25/26 (96) & 0.38 \\
\hline Response to therapy & $32(73)$ & $39(51)$ & 0.018 \\
\hline Death within 42 days of starting therapy & $2(5)$ & 7/76 (9) & 0.48 \\
\hline $\begin{array}{l}\text { Aspergillosis-attributable death within } 42 \text { days } \\
\text { of starting therapy }\end{array}$ & $2(5)$ & 6/76 (8) & 0.71 \\
\hline
\end{tabular}

${ }^{\mathrm{a}}$ One patient had all 3 types of IA infections

treatment rate, from 35 to $7 \%$, with no reported missed cases of IA. However, one case of zygomycosis was missed and diagnosed post-mortem. In addition, the study was conducted in a small subgroup of patients [19].

Girmenia et al. [22] designed an intensive diagnostic workup strategy that led to $43 \%$ decreased use of antifungal therapy with no undetected invasive fungal disease at 3 months after follow-up in 159 cases of neutropenic fever. In contrast, Cordonnier et al. [14] showed that overall mortality rate in the group treated with amphotericin $\mathrm{B}$ according to a preemptive or diagnostic strategy based on clinical factors or GM in persistent neutropenia was not inferior to that in the group treated empirically.

Another randomized trial done in multiple Australian centers showed that the use of biomarkers to treat suspected IA has decreased the rates of empiric therapy without affecting mortality rates [20]. Aguilar-Guisado et al. [17] conducted a study in hematologic malignancy patients with persistent febrile neutropenia and administered antifungal therapy only to the group who fulfilled a set of diagnostic criteria. In that study, $38 \%$ of the 
Table 3 Predictors of response to primary therapy in patients with hematologic malignancy and aspergillosis

\begin{tabular}{|c|c|c|c|c|c|}
\hline \multirow[t]{2}{*}{ Variables } & \multicolumn{3}{|c|}{ Univariate analysis } & \multicolumn{2}{|l|}{ Multivariate analysis } \\
\hline & $\begin{array}{l}\text { Response } \\
(n=101) \\
N(\%)\end{array}$ & $\begin{array}{l}\text { No-Response } \\
(n=241) \\
N(\%)\end{array}$ & $p$-value & OR $(95 \% \mathrm{Cl})$ & $p$-value \\
\hline Age (years), median (range) & $59(14-81)$ & $52(16-86)$ & 0.007 & & - \\
\hline Gender, male & $60(59)$ & $143(59)$ & 0.99 & & \\
\hline Diagnosis of invasive aspergillosis & & & 0.024 & & - \\
\hline Definite & $22 / 100(22)$ & $83(34)$ & & & \\
\hline Probable & 78/100 (78) & $158(66)$ & & & \\
\hline Type of IA infection ${ }^{a}$ & & & $<.001$ & & $<.0001$ \\
\hline Invasive pulmonary infection & $84(83)$ & $202(84)$ & & $0.12(0.04,0.34)$ & $(<.0001)$ \\
\hline Disseminated infection & $1(1)$ & $24(10)$ & & $0.02(<0.01,0.16)$ & $(<.0001)$ \\
\hline Localized or sinus infection & $16(16)$ & $15(6)$ & & Referent & \\
\hline Type of cancer & & & 0.03 & & - \\
\hline Leukemia & $66 / 98(67)$ & 189/240 (79) & & & \\
\hline Lymphoma & 23/98 (23) & $43 / 240(18)$ & & & \\
\hline Myeloma & 9/98 (9) & $8 / 240(3)$ & & & \\
\hline Transplantation within 1 year prior to infection & $34(34)$ & $98 / 240(41)$ & 0.21 & & - \\
\hline Type of transplantation within prior year & & & 0.26 & & \\
\hline Allogeneic transplant & 27/34 (79) & 86/98 (88) & & & \\
\hline Autologous transplant & $7 / 34(21)$ & $12 / 98(12)$ & & & \\
\hline Graft vs Host Disease (GVHD) & $18 / 27(67)$ & $64 / 86(74)$ & 0.43 & & - \\
\hline Neutropenia $(<500$ ANC) at onset of IA & 31/94 (33) & 126/237 (53) & 0.001 & & - \\
\hline Persistent neutropenia & $30 / 79(38)$ & $92 / 231(40)$ & 0.77 & & \\
\hline Received immunotherapy & 38/99 (38) & $163 / 240(68)$ & $<.0001$ & & - \\
\hline Received WBC transfusion & $5 / 100(5)$ & $50 / 240(21)$ & $<.001$ & $0.21(0.05,0.66)$ & 0.005 \\
\hline Year of IA diagnosis/treatment & & & $<.0001$ & & - \\
\hline 1993-2004 & $32(32)$ & $154(64)$ & & & \\
\hline 2005-2016 & $69(68)$ & $87(36)$ & & & \\
\hline Prophylactic antifungal treatment prior to infection & 23/100 (23) & $89(37)$ & 0.013 & & - \\
\hline Breakthrough & 22/23 (96) & $76 / 88(86)$ & 0.30 & & \\
\hline Primary therapy strategy & & & $<.0001$ & & $<.0001$ \\
\hline Diagnostic-driven therapy with voriconazole & $32(32)$ & $12(5)$ & & Referent & \\
\hline Empiric antifungal therapy without voriconazole & $30(30)$ & $191(79)$ & & $0.05(0.02,0.12)$ & $(<.0001)$ \\
\hline Empiric antifungal therapy with voriconazole & $39(39)$ & $38(16)$ & & $0.41(0.16,1.02)$ & $(0.06)$ \\
\hline
\end{tabular}

${ }^{a}$ All patients with more than one types of IA infections in this study had invasive pulmonary infection and were included in invasive pulmonary infection category in this analysis

patients were not treated with antifungal drugs, and none in this subgroup had a final diagnosis of a fungal infection. However, in the treated group, $40 \% \mathrm{had}$ non-fungal infections and $42.3 \%$ had a diagnosis of probable or possible IA; their primary therapy consisted mainly of caspofungin and voriconazole based on the most likely fungal etiology [17].

Consistent with findings in previous reports [23-25], we also demonstrated that DDA-Vori therapy was associated with better outcome in terms of response and
IA-attributable mortality when compared with EMPnon-Vori. As noted earlier, most (80.5\%) of the patients who received EMP-non-Vori were on a regimen that included a lipid formulation of amphotericin B. DDA-Vori therapy was associated with equivalent outcome when compared with EMP-Vori therapy.

Voriconazole has been suggested as the primary treatment for invasive pulmonary and extrapulmonary aspergillosis by the Infectious Disease Society of America [10]. When voriconazole treatment was compared with 
Table 4 Predictors of mortality within 42 days of initiation of IA therapy in patients with hematologic malignancy and aspergillosis

\begin{tabular}{|c|c|c|c|c|c|}
\hline \multirow[t]{2}{*}{ Variables } & \multicolumn{3}{|l|}{ Univariate } & \multicolumn{2}{|c|}{ Multivariate analysis } \\
\hline & $\begin{array}{l}\text { Dead } \\
(n=132) \\
N(\%)\end{array}$ & $\begin{array}{l}\text { Alive } \\
(n=208) \\
N(\%)\end{array}$ & $p$-value & $\mathrm{HR}(95 \% \mathrm{Cl})$ & $p$-value \\
\hline Age (years), median (range) & $50(16-80)$ & $56(14-86)$ & 0.07 & & - \\
\hline Gender, male & $84(64)$ & $119(57)$ & 0.24 & & - \\
\hline Diagnosis of invasive aspergillosis & & & 0.001 & & 0.023 \\
\hline Definite & $54(41)$ & $50 / 207(24)$ & & $1.5(1.1,2.2)$ & \\
\hline Probable & $78(59)$ & 157/207 (76) & & Referent & \\
\hline Type of IA infection ${ }^{a}$ & & & 0.16 & & 0.007 \\
\hline Invasive pulmonary infection & $111(84)$ & $174(84)$ & & $3.3(1.5,7.2)$ & $(0.003)$ \\
\hline Disseminated infection & $13(10)$ & $12(6)$ & & $4.0(1.6,10.3)$ & $(0.003)$ \\
\hline Localized or sinus infection & $8(6)$ & $22(11)$ & & Referent & \\
\hline Type of cancer & & & 0.05 & & - \\
\hline Leukemia & 106/131 (81) & $148 / 205(72)$ & & & \\
\hline Lymphoma & 23/131 (18) & $43 / 205(21)$ & & & \\
\hline Myeloma & $2 / 131(2)$ & $14 / 205(7)$ & & & \\
\hline Transplantation within 1 year prior to infection & $41 / 131(31)$ & $91(44)$ & 0.022 & $0.60(0.41,0.88)$ & 0.008 \\
\hline Type of transplantation within prior year & & & 0.06 & & \\
\hline Allogeneic transplant & $39 / 41(95)$ & $74 / 91(81)$ & & & \\
\hline Autologous transplant & 2/41 (8) & 17/91 (19) & & & \\
\hline Graft vs Host Disease (GVHD) & 29/39 (74) & $53 / 74(72)$ & 0.76 & & \\
\hline Neutropenia $(<500 \mathrm{ANC})$ at onset of IA & $79 / 130(61)$ & 76/199 (38) & $<.0001$ & & - \\
\hline Persistent neutropenia & $59 / 130(45)$ & $63 / 179(35)$ & 0.07 & & - \\
\hline Received immunotherapy & $92(70)$ & 108/205 (53) & 0.002 & & - \\
\hline Received WBC transfusion & $31(23)$ & $24 / 206(12)$ & 0.004 & & - \\
\hline Year of IA diagnosis/treatment & & & $<.0001$ & & - \\
\hline 1993-2004 & $99(75)$ & $87(42)$ & & & \\
\hline $2005-2016$ & $33(25)$ & $121(58)$ & & & \\
\hline Prophylactic antifungal treatment prior to infection & $36(27)$ & $76 / 207(37)$ & 0.07 & $0.61(0.41,0.90)$ & 0.012 \\
\hline Breakthrough & $29 / 36(81)$ & $69 / 75(92)$ & 0.11 & & \\
\hline Primary therapy strategy & & & $<.0001$ & & $<.0001$ \\
\hline Diagnostic-driven therapy with voriconazole & $2(2)$ & $42(20)$ & & Referent & \\
\hline Empiric antifungal therapy without voriconazole & $123(93)$ & $97(47)$ & & $18.0(4.4,73.2)$ & $(<.0001)$ \\
\hline Empiric antifungal therapy with voriconazole & $7(5)$ & $69(33)$ & & $2.2(0.5,10.6)$ & $(0.33)$ \\
\hline
\end{tabular}

$I A=$ Invasive aspergillosis; $W B C=$ White blood cell; $H R=$ Hazard ratio; $95 \% C l=95 \%$ Confidence interval

${ }^{a}$ All patients with more than one types of IA infections in this study had invasive pulmonary infection and were included in invasive pulmonary infection category in this analysis

amphotericin B as primary treatment for possible, probable, and proven IA infections, it showed better survival and response rates among the proven and probable infection groups and showed better response rates in the possible infection group [26]. The fact that EMP-Vori and DDA-Vori were not statistically different further emphasizes the importance of targeted therapy using the appropriate agent and its role in preventing overtreatment without compromising care in this critical patient population. We also noticed that the decreased mortality observed from the year 2004 corresponded to the period when voriconazole was introduced in our medical center.

Anti-mold prophylaxis was found to be a positive predictor of survival. It is possible that anti-mold prophylaxis partially decreases the fungal burden in infected patients, hence ameliorating the course of IA. This is evident by the fact that the aspergillus galactomannan enzyme immunoassay is markedly affected by concomitant administration of prophylactic anti-mold drugs. It is 


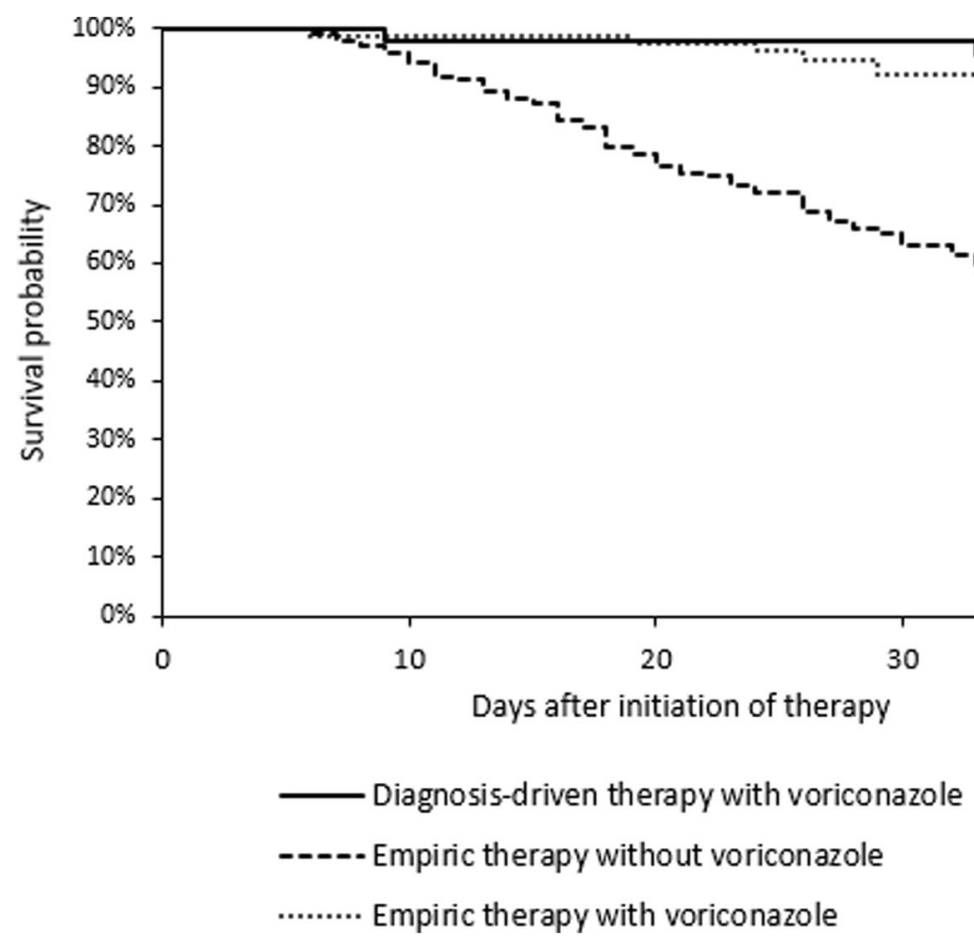

Fig. 1 Kaplan-Meier Survival Curves of Patients with Different Therapies

a well-known fact that GM levels are directly proportional to the degree of fungal burden and hence prognostically predict a worst outcome $[4,7,27]$.

The excessive use of antifungals, however, in the empiric treatment of suspected possible IA could play a role in the emergence of resistance (particularly azole resistance) among Aspergillus species, which is associated with treatment failure and elevated rates of breakthrough infections that are difficult to treat with an azole-containing regimen [28]. Multiple point mutations have been determined at the molecular level among strains recovered from patients receiving triazole anti-mold treatment. The resulting amino acid substitutions are believed to be associated with the emerging Aspergillus antifungal resistance [29].

In addition, there could be a cost benefit associated with the DDA. A meta-analysis published in 2015 assessed and compared the total costs associated with empiric and preemptive therapy, in which most of the included studies were based on GM and imaging studies. This analysis found an average reduction of $\$ 324$ per patient of the total cost, considering the workup and antifungal medications [30]. This needs to be further evaluated in future prospective studies at our center.

This study had some limitations because of its retrospective nature and because it was conducted in a single medical center. Compared to the other two groups, the sample size of DDA-Vori group was small $(n=44)$. We didn't account for the status of the malignant disease at the time of diagnosis (remission vs relapse/refractory disease), intensity of Graft vs Host Disease (GVHD) and comorbidities/coinfections.

The strength of this study was its inclusion of a large cohort of hematologic malignancy patients and post-HSCT patients having probable or proven IA. However, the numbers of patients receiving DDA-Vori was smaller than the numbers receiving the other two therapies, which was another limitation. The results apply to our population of hematological malignancies and HSCT but cannot be extrapolated to solid organ transplant or other populations.

\section{Conclusions}

In conclusion, the DDA could reduce the use of unnecessary antifungals with a superior to equivalent outcome. This approach allows for a more rational utilization of available antifungals with potential reduction in costs and adverse events associated with the widespread use of empiric therapy. In addition, this targeted diagnostic-driven therapy could lead to improved quality of care in this high-risk patient population.

\section{Abbreviations}

BAL: Bronchoalveolar Lavage; CT: Computed Tomographic; DDA: DiagnosticDriven Approach; DDA-Vori: Diagnostic Driven DDA; EMP-Non-Vori: NonVoriconazole-Containing Regimen; EMP-Vori: Empiric Therapy With

Voriconazole; EORTC/MSG: European Organization For Research And 
Treatment Of Cancer/Invasive Fungal Infections Cooperative Group And The National Institute Of Allergy And Infectious Diseases Mycoses Study Group; GM: Galactomannan; HSCT: Hematopoietic Stem Cell Transplantation; IA: Invasive Aspergillosis

\section{Acknowledgments}

We thank Ms. Locke, Tamara K at the Department of Scientific Publications, at The University of Texas MD Anderson Cancer Center for copyediting the manuscript.

\section{Funding}

This work was supported by industry funding from Pfizer pharmaceutical company. The funders had no role in study design, data collection and interpretation, or the decision to submit the work for publication.

\section{Availability of data and materials}

All data generated or analyzed during this study are included in this published article and its files. Datasets used and/or analysed during the current study are available from the corresponding author on reasonable request.

\section{Author's contributions}

RWD (Writing and Collecting data); RYH (Design, Critical Editing, Review Data); A-MC (Review Data, Editing); FG (Collecting Data); YJ (Analysis, Editing Results); IR (Design, Critical Editing, Interpretation of Results). All authors read and approved the final manuscript.

\section{Ethics approval and consent to participate}

The MD Anderson Cancer Center Institutional Review Board has reviewed and approved this retrospective study and a waiver of informed consent was obtained.

\section{Consent for publication}

Not applicable.

\section{Competing interests}

The authors declare that they have no competing interests. IR is a consultant and speaker with Pfizer.IR, A-MC and RH are recipients of Pfizer study grants over the last 5 years.

\section{Publisher's Note}

Springer Nature remains neutral with regard to jurisdictional claims in published maps and institutional affiliations.

\section{Received: 5 September 2018 Accepted: 3 December 2018} Published online: 13 December 2018

\section{References}

1. Nicolle MC, Benet T, Thiebaut A, Bienvenu AL, Voirin N, Duclos A, Sobh M, Cannas G, Thomas X, Nicolini FE, et al. Invasive aspergillosis in patients with hematologic malignancies: incidence and description of 127 cases enrolled in a single institution prospective survey from 2004 to 2009. Haematologica. 2011;96(11):1685-91

2. Pagano L, Caira M, Candoni A, Offidani M, Fianchi L, Martino B, Pastore D, Picardi M, Bonini A, Chierichini A, et al. The epidemiology of fungal infections in patients with hematologic malignancies: the SEIFEM-2004 study. Haematologica. 2006;91(8):1068-75.

3. Kontoyiannis DP, Marr KA, Park BJ, Alexander BD, Anaissie EJ, Walsh TJ, Ito J, Andes DR, Baddley JW, Brown JM, et al. Prospective surveillance for invasive fungal infections in hematopoietic stem cell transplant recipients, 20012006: overview of the transplant-associated infection surveillance network (TRANSNET) database. Clin Infect Dis. 2010;50(8):1091-100.

4. Maertens JA, Blennow O, Duarte RF, Munoz P. The current management landscape: aspergillosis. J Antimicrob Chemother. 2016;71(suppl 2):ii23-9.

5. Maertens JA, Nucci M, Donnelly JP. The role of antifungal treatment in hematology. Haematologica. 2012;97(3):325-7.

6. Leeflang MM, Debets-Ossenkopp YJ, Wang J, Visser CE, Scholten RJ, Hooft L, Bijlmer HA, Reitsma JB, Zhang M, Bossuyt PM, et al. Galactomannan detection for invasive aspergillosis in immunocompromised patients. Cochrane Database Syst Rev. 2015;12:CD007394.
7. Marr KA, Laverdiere M, Gugel A, Leisenring W. Antifungal therapy decreases sensitivity of the aspergillus galactomannan enzyme immunoassay. Clin Infect Dis. 2005;40(12):1762-9.

8. Hachem R, Sumoza D, Hanna H, Girgawy E, Munsell M, Raad I. Clinical and radiologic predictors of invasive pulmonary aspergillosis in cancer patients: should the European Organization for Research and Treatment of Cancer/ mycosis study group (EORTC/MSG) criteria be revised? Cancer. 2006;106(7): 1581-6.

9. Greene RE, Schlamm HT, Oestmann JW, Stark P, Durand C, Lortholary O, Wingard JR, Herbrecht R, Ribaud P, Patterson TF, et al. Imaging findings in acute invasive pulmonary aspergillosis: clinical significance of the halo sign. Clin Infect Dis. 2007:44(3):373-9.

10. Patterson TF, Thompson GR 3rd, Denning DW, Fishman JA, Hadley S, Herbrecht R, Kontoyiannis DP, Marr KA, Morrison VA, Nguyen MH, et al. Practice guidelines for the diagnosis and Management of Aspergillosis: 2016 update by the Infectious Diseases Society of America. Clin Infect Dis. 2016; 63(4):e1-e60.

11. De Pauw B, Walsh TJ, Donnelly JP, Stevens DA, Edwards JE, Calandra T, Pappas PG, Maertens J, Lortholary O, Kauffman CA, et al. Revised definitions of invasive fungal disease from the European Organization for Research and Treatment of Cancer/invasive fungal infections cooperative group and the National Institute of Allergy and Infectious Diseases mycoses study group (EORTC/MSG) consensus group. Clin Infect Dis. 2008;46(12):1813-21.

12. Okuturlar Y, Ozkalemkas F, Ener B, Serin SO, Kazak E, Ozcelik T, Ozkocaman $\checkmark$, Ozkan HA, Akalin H, Gunaldi M, et al. Serum galactomannan levels in the diagnosis of invasive aspergillosis. Korean J Intern Med. 2015;30(6):899-905.

13. D'Haese J, Theunissen $K$, Vermeulen $E$, Schoemans $H$, De Vlieger $G$, Lammertijn L, Meersseman P, Meersseman W, Lagrou K, Maertens J. Detection of galactomannan in bronchoalveolar lavage fluid samples of patients at risk for invasive pulmonary aspergillosis: analytical and clinical validity. J Clin Microbiol. 2012;50(4):1258-63.

14. Cordonnier C, Pautas C, Maury S, Vekhoff A, Farhat H, Suarez F, Dhedin N, Isnard F, Ades L, Kuhnowski F, et al. Empirical versus preemptive antifungal therapy for high-risk, febrile, neutropenic patients: a randomized, controlled trial. Clin Infect Dis. 2009;48(8):1042-51.

15. Pizzo PA, Robichaud KJ, Gill FA, Witebsky FG. Empiric antibiotic and antifungal therapy for cancer patients with prolonged fever and granulocytopenia. Am J Med. 1982;72(1):101-11.

16. Freifeld AG, Bow EJ, Sepkowitz KA, Boeckh MJ, Ito Jl, Mullen CA, Raad II, Rolston KV, Young JAH, Wingard JR. Clinical practice guideline for the use of antimicrobial agents in neutropenic patients with Cancer: 2010 update by the Infectious Diseases Society of America. Clin Infect Dis. 2011;52(4):427-31.

17. Aguilar-Guisado M, Martín-Peña A, Espigado I, Ruiz Pérez de Pipaon M, Falantes J, de la Cruz F, Cisneros JM. Universal antifungal therapy is not needed in persistent febrile neutropenia: a tailored diagnostic and therapeutic approach. Haematologica. 2012;97(3):464-71.

18. Dignan FL, Evans SO, Ethell ME, Shaw BE, Davies FE, Dearden CE, Treleaven JG, Riley UBG, Morgan GJ, Potter MN. An early CT-diagnosis-based treatment strategy for invasive fungal infection in allogeneic transplant recipients using caspofungin first line: an effective strategy with low mortality. Bone Marrow Transpl. 2009:44(1):51-6.

19. Maertens J, Theunissen K, Verhoef G, Verschakelen J, Lagrou K, Verbeken E, Wilmer A, Verhaegen J, Boogaerts M, Van Eldere J. Galactomannan and computed tomography - based preemptive antifungal therapy in neutropenic patients at high risk for invasive fungal infection: a prospective feasibility study. Clin Infect Dis. 2005;41(9):1242-50.

20. Morrissey CO, Chen SCA, Sorrell TC, Milliken S, Bardy PG, Bradstock KF, Szer J, Halliday CL, Gilroy NM, Moore J, et al. Galactomannan and PCR versus culture and histology for directing use of antifungal treatment for invasive aspergillosis in high-risk haematology patients: a randomised controlled trial. Lancet Infect Dis. 2013;13(6):519-28.

21. Tan BH, Low JG, Chlebicka NL, Kurup A, Cheah FK, Lin RT, Goh YT, Wong GC. Galactomannan-guided preemptive vs. empirical antifungals in the persistently febrile neutropenic patient: a prospective randomized study. Int J Infect Dis. 2011;15(5):e350-6.

22. Girmenia C, Micozzi A, Gentile G, Santilli S, Arleo E, Cardarelli L, Capria S, Minotti C, Cartoni C, Brocchieri S, et al. Clinically driven diagnostic antifungal approach in neutropenic patients: a prospective feasibility study. J Clin Oncol. 2010;28(4):667-74.

23. Ramos ER, Jiang Y, Hachem R, Kassis C, Kontoyiannis DP, Raad I. Outcome analysis of invasive aspergillosis in hematologic malignancy and 
hematopoietic stem cell transplant patients: the role of novel antimold azoles. Oncologist. 2011;16(7):1049-60.

24. Raad II, El Zakhem A, El Helou G, Jiang Y, Kontoyiannis DP, Hachem R. Clinical experience of the use of voriconazole, caspofungin or the combination in primary and salvage therapy of invasive aspergillosis in haematological malignancies. Int J Antimicrob Ag. 2015;45(3):283-8.

25. Herbrecht R, Denning DW, Patterson TF, Bennett JE, Greene RE, Oestmann JW, Kern WW, Marr KA, Ribaud P, Lortholary O, et al. Voriconazole versus amphotericin B for primary therapy of invasive aspergillosis. N Engl I Med. 2002;347(6):408-15.

26. Herbrecht R, Patterson TF, Slavin MA, Marchetti O, Maertens J, Johnson EM, Schlamm HT, Donnelly JP, Pappas PG. Application of the 2008 definitions for invasive fungal diseases to the trial comparing voriconazole versus amphotericin B for therapy of invasive aspergillosis: a collaborative study of the mycoses study group (MSG 05) and the European Organization for Research and Treatment of Cancer infectious diseases group. Clin Infect Dis. 2015;60(5):713-20.

27. Mennink-Kersten MA, Donnelly JP, Verweij PE. Detection of circulating galactomannan for the diagnosis and management of invasive aspergillosis. Lancet Infect Dis. 2004;4(6):349-57.

28. Arendrup MC. Update on antifungal resistance in aspergillus and Candida. Clin Microbiol Infect. 2014;20(Suppl 6):42-8.

29. Garcia-Rubio R, Cuenca-Estrella M, Mellado E. Triazole resistance in aspergillus species: an emerging problem. Drugs. 2017;77(6):599-613.

30. Fung M, Kim J, Marty FM, Schwarzinger M, Koo S. Meta-analysis and cost comparison of empirical versus pre-Emptive antifungal strategies in hematologic malignancy patients with high-risk febrile neutropenia. PLoS One. 2015;10(11):e0140930.

Ready to submit your research? Choose BMC and benefit from:

- fast, convenient online submission

- thorough peer review by experienced researchers in your field

- rapid publication on acceptance

- support for research data, including large and complex data types

- gold Open Access which fosters wider collaboration and increased citations

- maximum visibility for your research: over $100 \mathrm{M}$ website views per year

At $\mathrm{BMC}$, research is always in progress.

Learn more biomedcentral.com/submissions 